\title{
Efficient Hydrogenation of Xylose and Hemicellulosic Hydrolysate to Xylitol over Ni-Re Bimetallic Nanoparticle Catalyst
}

\author{
Haian Xia ${ }^{1,2, * \mathbb{C}}$, Lei Zhang ${ }^{1,2}$, Hong Hu ${ }^{1,2}$, Songlin Zuo ${ }^{1,2}$ and Li Yang ${ }^{1,2, *}$ \\ 1 Jiangsu Provincial Key Lab for the Chemistry and Utilization of Agro-Forest Biomass, College of Chemical \\ Engineering, Nanjing Forestry University, Nanjing 210037, China; lzhang1117@163.com (L.Z.); \\ honghu@njfu.edu.cn (H.H.); zuosl@hotmail.com (S.Z.) \\ 2 Jiangsu Co-Innovation Center of Efficient Processing and Utilization of Forest Resources, \\ Nanjing Forestry University, Nanjing 210037, China \\ * Correspondence: haxia@dicp.ac.cn (H.X.); yangli163@163.com (L.Y.); Tel.: +86-25-8542-7635 (H.X.); \\ +86-25-8542-7774 (L.Y.)
}

Received: 5 December 2019; Accepted: 27 December 2019; Published: 30 December 2019

\begin{abstract}
A disadvantage of the commercial Raney $\mathrm{Ni}$ is that the $\mathrm{Ni}$ active sites are prone to leaching and deactivation in the hydrogenation of xylose to xylitol. To explore a more stable and robust catalyst, activated carbon (AC) supported Ni-Re bimetallic catalysts (Ni-Re/AC) were synthesized and used to hydrogenate xylose and hemicellulosic hydrolysate into xylitol under mild reaction conditions. In contrast to the monometallic $\mathrm{Ni} / \mathrm{AC}$ catalyst, bimetallic Ni-Re/AC exhibited better catalytic performances in the hydrogenation of xylose to xylitol. A high xylitol yield up to $98 \%$ was achieved over $\mathrm{Ni}-\mathrm{Re} / \mathrm{AC}\left(\mathrm{n}_{\mathrm{Ni}}: \mathrm{n}_{\mathrm{Re}}=1: 1\right)$ at $140^{\circ} \mathrm{C}$ for $1 \mathrm{~h}$. In addition, these bimetallic catalysts also had superior hydrogenation performance in the conversion of the hydrolysate derived from the hydrolysis reaction of the hemicellulose of Camellia oleifera shell. The characterization results showed that the addition of Re led to the formation of Ni-Re alloy and improved the dispersion of $\mathrm{Ni}$ active sites. The recycled experimental results revealed that the monometallic $\mathrm{Ni}$ and the bimetallic $\mathrm{Ni}$-Re catalysts tended to deactivate, but the introduction of Re was able to remarkably improve the catalyst's stability and reduce the Ni leaching during the hydrogenation reaction.
\end{abstract}

Keywords: xylose; xylitol; Ni-Re alloy; hydrogenation; electron transfer

\section{Introduction}

The depletion of fossil resources has attracted considerable interest in the valorization of renewable biomass materials for the production of valuable chemicals. The catalytic conversion of naturally occurring sugars, such as xylose and glucose, into their corresponding sugar alcohols is an attractive pathway for the production of value added chemicals, such as sweeteners and pharmaceutical intermediates [1-11]. Xylitol is an important artificial sweetener and has been widely used in various fields [12-16]. At present, the production of xylitol proceeds mainly through the reduction reaction of xylose derived from the hydrolysis of corncob [17-22]. Camellia oleifera is a woody oil crop that is distributed in the southern provinces of China [23-26]. The seeds of camellia oleifera are used to produce an edible oil, which contains plentiful vitamins and unsaturated fatty acids and is comparable to the well known olive oil. However, Camellia oleifera shell, generated from the process residues, is usually neglected and still not used efficiently. More than three million tons of Camellia oleifera shell are annually produced as agricultural waste, and most of this is burned to provide thermal power [25]. Camellia oleifera shell is a lignocellulosic biomass that is composed of a high content of hemicellulose 
and lignin and a low content of cellulose. Therefore, Camellia oleifera shell is considered as an alternative raw material to corncob for the production of xylose and xylitol due to its high hemicellulose content.

The catalytic hydrogenation of xylose into xylitol is traditionally performed in a three phase slurry batch reactor on Raney Ni catalysts (Scheme 1) [12,27]. The Raney Ni catalyst exhibited high activity and excellent xylitol yield with corn stover hydrolysate as a starting material [28]. The main advantages of Raney Ni catalyst were its low price, good activity, and high selectivity. However, a major disadvantage of Raney Ni catalysts is their easy deactivation due to Ni metal leaching and the deposition of the reaction byproducts on the surface active Ni sites [14,27,29,30]. Moreover, Ni ions leached into xylitol solution must be removed when xylitol is used in the food industry or as medicine, which leads to an increase in the production cost of xylitol because of expensive purification steps. In recent years, much effort has been undertaken to develop more stable and recyclable catalysts for the hydrogenation of xylose into xylitol [28,31-33]. Pecchi et al. successfully prepared Ni containing perovskite-type oxides, such as $\mathrm{La}_{1-x} \mathrm{Ce}_{x} \mathrm{Al}_{0.18} \mathrm{Ni}_{0.82} \mathrm{O}_{3}(x=0.0,0.1,0.5,0.7)$ and $\mathrm{Nd}_{1-x} \mathrm{Ce}_{x} \mathrm{Al}_{0.16} 2 \mathrm{Ni}_{0.838} \mathrm{O}_{3}(x=0.0,0.1,0.5,0.7)$ catalysts, for the hydrogenation of xylose to xylitol [30,31]. In their work, the reaction products were composed of xylitol, xylulose, glycerol, and ethylene glycol, and selectivity toward xylitol up to $50 \%$ was obtained at $100{ }^{\circ} \mathrm{C}$ under 25 bar $\mathrm{H}_{2}$ pressure [30]. Moreover, it was found that the formation of crystalline structures rendered substantial leaching resistant catalysts because no significant $\mathrm{Ni}$ leaching was detected in aqueous medium for these catalysts with Ce-free, as well as 50\% and 70\% Ce contents [30]. It is still a great challenge to develop novel catalysts with highly stable and excellent xylitol selectivity in the catalytic hydrogenation of xylose under mild conditions.

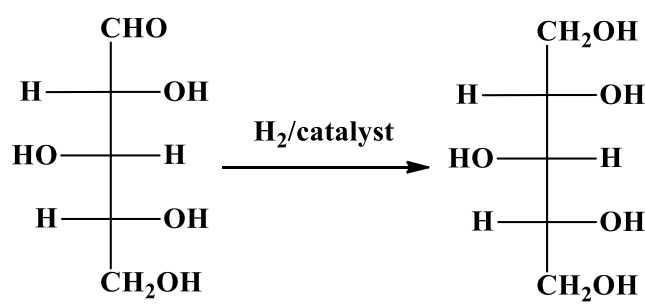

Scheme 1. Hydrogenation of xylose to xylitol.

In addition to the $\mathrm{Ni}$ based catalysts, various noble metals, such as $\mathrm{Pt}, \mathrm{Pd}$, and $\mathrm{Ru}$, have been utilized for the catalytic hydrogenation of xylose to xylitol [29,34-36]. It has been reported that Ru based catalysts exhibit good catalytic performance and no leaching occurred during the xylose hydrogenation reaction [14,36], which is an alternative catalyst to Raney Ni. For example, Hemandez-Mejia et al. reported that $\mathrm{Ru}$ supported on rutile titania afforded $100 \%$ xylose conversion and up to $98 \%$ xylose yield at $120^{\circ} \mathrm{C}$ in $15 \mathrm{~min}$ [36]. Nevertheless, in comparison with the $\mathrm{Ni}$ based catalyst, the use of a noble metal catalyst is very expensive and not the most desirable choice for a large scale xylose hydrogenation process.

It has been revealed that the application of bimetallic catalysts could remarkably boost the catalytic activity and improve the stability [37-40]. Zhu et al. reported that the bimetallic Ni-Re catalysts had better hydrodeoxygenation performances of phenol into benzene compared to the monometallic Ni catalyst due to the geometric effect and electronic effect after the introduction of Re metal [38]. However, Mikkola et al. revealed that a Mo promoted Raney Ni catalyst was prone to deactivation due to the collapse of the catalyst pore structure and leaching of the promoter metals, Mo and alumina [27]. It has been widely reported that most metal oxide supports are unstable and prone to undergo structural destruction or component leaching in aqueous hydrogenation reactions. AC has been shown to have a good resistance to acids and bases, and it contains a variety of surface oxygen-containing functional groups which can strongly anchor the active metal sites. Thus, AC is an excellent support for most metal nanoparticle catalysts [41]. Therefore, it is of great significance for the development of a more stable and efficient bimetallic Ni-based catalyst in the catalytic hydrogenation of xylose. 
In this work, activated carbon (AC) supported Ni-Re bimetallic catalysts with various $\mathrm{Ni} / \mathrm{Re}$ ratios were synthesized via the impregnation method. The aim of the use of supported catalysts is to decrease the Ni loading and enhance its mechanistic intensity, thereby decreasing the catalyst cost. The incorporation of Re into $\mathrm{N}$ based catalysts is to enhance its catalytic activity, as well as improve its hydrothermal stability and decrease Ni leaching. The catalytic performances of these catalysts were evaluated by the hydrogenation of xylose and hydrolysate containing xylose derived from the hydrolysis of Camellia oleifera shell. The physicochemical properties of various catalysts were characterized by X-ray photoelectron spectroscopy (XPS), X-ray diffraction (XRD), CO chemisorption, and transmission electron microscope (TEM) techniques. The deactivated mechanism of these catalysts was also discussed.

\section{Materials and Methods}

\subsection{Catalyst Preparation}

The monometallic Ni/AC or Re/AC and the bimetallic Ni-Re/AC catalysts with different $\mathrm{Ni} / \mathrm{Re}$ ratios were synthesized by the wet impregnation method. The activated carbon was derived from coconut husk produced by steaming activation $\left(\mathrm{S}_{\mathrm{BET}}=1500 \mathrm{~m}^{2} / \mathrm{g}\right) \cdot \mathrm{Ni}\left(\mathrm{NO}_{3}\right)_{2} \cdot 6 \mathrm{H}_{2} \mathrm{O}$ and $\mathrm{NH}_{4} \mathrm{ReO}_{4}$ were used for the catalyst precursors. A typical synthesis procedure is described as follows. First, desired amounts of $\mathrm{Ni}\left(\mathrm{NO}_{3}\right)_{2} \cdot 6 \mathrm{H}_{2} \mathrm{O}$ and $\mathrm{NH}_{4} \mathrm{ReO}_{4}$ were dissolved into deionized water, and then, the activated carbon was added into the aforementioned aqueous solution. Subsequently, the mixture was stirred for $12 \mathrm{~h}$, followed by removing water using a rotary evaporator. Finally, the resulted solid was calcined at $500{ }^{\circ} \mathrm{C}$ in $\mathrm{N}_{2}$ flow for $2 \mathrm{~h}$ and then was reduced in $1 \mathrm{vol} \% \mathrm{H}_{2} / \mathrm{N}_{2}$ flow at the same temperature for $2 \mathrm{~h}$. The Ni loading of the catalysts was fixed to $5 \mathrm{wt} \%$, and the Ni/Re ratios were 10:1, 4:1, 2:1, and 1:1. The catalysts were denoted as: $\mathrm{Ni}-\operatorname{Re} / \mathrm{AC}\left(\mathrm{n}_{\mathrm{Ni}}: \mathrm{n}_{\mathrm{Re}}=\mathrm{x}: \mathrm{y}\right)$, where $\mathrm{n}_{\mathrm{Ni}}: \mathrm{n}_{\mathrm{Re}}$ refers to the $\mathrm{Ni} / \mathrm{Re}$ molar ratio. For comparison, a Re/AC with Re content of $15.8 \%$ was also fabricated, and its $\operatorname{Re}$ content was equal to that of $\mathrm{Ni}-\mathrm{Re} / \mathrm{AC}\left(\mathrm{n}_{\mathrm{Ni}}: \mathrm{n}_{\mathrm{Re}}=1: 1\right)$.

\subsection{Catalyst Characterization}

The XRD patterns were recorded on a Rigaku Ultima IV X-ray diffractometer (Rigaku, Matsubaracho, Japan) equipped with a $\mathrm{Cu} \mathrm{K} \alpha$ X-ray source operating at $40 \mathrm{kV}$ and $30 \mathrm{~mA}$. The TEM images were measured on a JEM-200CX transmission electron microscope (JEOL, Tokyo, Japan). The size of every particle was obtained through measuring its spherical diameter by the manual approach, and then, a mean particle size was calculated by averaging the diameters of $\sim 300$ particles. The XPS analyses were performed using a KRATOS AXIS Ultra DLD instrument (Shimadzu, Tokyo, Japan). An $\mathrm{Al} \mathrm{K} \alpha \mathrm{X}$-ray source was used for all samples, along with pressure in the analysis chamber of $7 \times 10^{-8} \mathrm{~Pa}$. The step size of $1 \mathrm{eV}$ and the dwell time of $0.1 \mathrm{~s}$ were employed, and each peak was scanned once for the survey scans.

The Ni dispersion was measured by CO chemisorption on an AutoChem II 2920 instrument (Micromeritics, Norcross, GA, USA). Prior to $\mathrm{CO}$ chemisorption, the samples were reduced at $500{ }^{\circ} \mathrm{C}$ for $1 \mathrm{~h}$ in flowing $\mathrm{H}_{2}$, followed by He purging for another $30 \mathrm{~min}$. Subsequently, the sample was cooled to $50{ }^{\circ} \mathrm{C}$, and then, $10 \% \mathrm{CO} / \mathrm{He}$ was pulsed into the reactor through the six port valve until a constant $\mathrm{CO}$ peak area was reached.

\subsection{The Preparation and Purification of Hydrolysate}

The hydrolysates were obtained by dilute sulfuric acid treatment of crushed Camellia oleifera shell, and the reaction results can be seen in Table S1 of the Supplementary Material. The liquid fraction was separated from the solid fraction by vacuum filtration. After the hydrolysis, the $\mathrm{pH}$ value of the hydrolyte was adjusted to ca. 5 using $\mathrm{CaCO}_{3}$, and the resulting gypsum was removed by filtration through vacuum filtration. After the neutralization, the resulting solution was further purified by 
activated carbon and then ion exchanged resin. Finally, the purified solution was evaporated and concentrated to a desired concentration.

\subsection{Catalytic Reaction}

In a typical procedure, the catalyst $(0.10 \mathrm{~g})$, xylose or hydrolysates, and deionized water $(50 \mathrm{~mL})$ were added into a $100 \mathrm{~mL}$ stainless steel reactor. The reactor was purified with pure $\mathrm{N}_{2}$ and $\mathrm{H}_{2}$ for three cycles, respectively, and finally pressurized with $2 \mathrm{MPa}$ of $\mathrm{H}_{2}$ at room temperature. The autoclave was heated to a desired reaction temperature and kept at this temperature for $2 \mathrm{~h}$ under stirring. After the reaction, the autoclave was cooled to room temperature before the liquid solution was separated from solid catalyst by filtration. In each experiment, three parallel experiments were conducted, and the error was obtained within $5 \%$.

The liquid product was identified on an Agilent 1200 S LC (Agilent, Palo Alto, CA, USA) with a $\mathrm{NH}_{2}-\mathrm{S}$ column with a refractive index detector (RID) by using a mixture of acetonitrile and water (75:25) as a mobile phase at a flow rate of $0.8 \mathrm{~mL} / \mathrm{min}$ at $303 \mathrm{~K}$. The residual solid was washed with deionized water several times followed by drying at $333 \mathrm{~K}$ overnight. The conversion of xylose was determined. The xylose conversion and yields of xylitol were calculated according to Equations (1) and (2):

$$
\begin{gathered}
\text { Conversion }(\%)=(\text { xylose mole input in the reactor }- \text { xylose mole after the } \\
\text { reaction }) / \text { xylose input in the reactor } \times 100
\end{gathered}
$$

Yield $(\%)=$ xylitol mole after the reaction/xylose mole input in the reaction $\times 100$

The stability of the catalysts was tested for two or three successive runs. The catalysts after reaction were washed with deionized water several times before the next run. For the catalyst regeneration procedure, the recovered solid was firstly dried and then further reduced in $1 \mathrm{vol} \% \mathrm{H}_{2} / \mathrm{N}_{2}$ flow at $500{ }^{\circ} \mathrm{C}$ for $2 \mathrm{~h}$. The leaching percentage of $\mathrm{Ni}$ in the filtrate obtained from the first run reaction was determined by ICP-OES.

\section{Results and Discussion}

\subsection{XRD Results}

The XRD was used to study the crystalline structure of the monometallic Ni/AC, Re/AC, and bimetallic Ni-Re/AC catalysts. As shown in Figure 1A, for 5\% Ni/AC, several diffraction peaks were observed at $22.5^{\circ}, 44.5^{\circ}, 51.7^{\circ}$, and $76.4^{\circ}$. The peak at $22.5^{\circ}$ was assigned to the activated carbon support, whereas the three peaks at $44.5^{\circ}, 51.7^{\circ}$, and $76.4^{\circ}$ were ascribed to $\mathrm{Ni}(111), \mathrm{Ni}(200)$, and $\mathrm{Ni}$ (220) of face centered cubic (FCC) Ni nanoparticles [42,43], respectively. For the monometallic Re/AC $\left(15.8 \mathrm{wt} \%\right.$ ) catalyst (Figure $1(\mathrm{f})$ ), four diffraction peaks appeared at $37.5^{\circ}, 40.6^{\circ}, 42.6^{\circ}$, and $67.1^{\circ}$, which were attributed to $\operatorname{Re}(100), \operatorname{Re}(002), \operatorname{Re}(101)$, and $\operatorname{Re}(110)$ of hexagonal closed packed (HCP) $\operatorname{Re}$ metal [38], respectively. After the incorporation of Re species, the signal assigned to Ni (111) shifted to a small diffraction angle. With increasing Re content, besides the diffraction peaks related to $\mathrm{Ni}$ nanoparticles, two new signals at $38.8^{\circ}$ and $42.0^{\circ}$ were observed for the Ni-Re/AC $\left(\mathrm{n}_{\mathrm{Ni}}: \mathrm{n}_{\mathrm{Re}}=1: 1\right)$ catalyst. Moreover, the diffraction peak related to $\operatorname{Re}(100)$ at $2 \theta$ of $37.5^{\circ}$ shifted to a bigger value at $38.8^{\circ}$, and simultaneously, the signals assigned to $\operatorname{Re}(002)$, and $\operatorname{Re}(101)$ shifted to higher values (Figure 1B). The shift in their diffraction angles demonstrated that the lattice expansion of the Ni unit cell took place, likely due to the incorporation of Re into the Ni lattice during high temperature reduction. The results clearly suggested the formation of Ni-Re alloy in the bimetallic Ni-Re catalyst. In addition, there were no diffraction peaks ascribed to $\mathrm{ReO}_{x}$ species in the monometallic $\mathrm{Re} / \mathrm{AC}$ or the bimetallic $\mathrm{Ni}-\mathrm{Re}$ catalysts, indicating that $\mathrm{ReO}_{x}$ species could be highly dispersed on all Ni-Re/AC samples. 

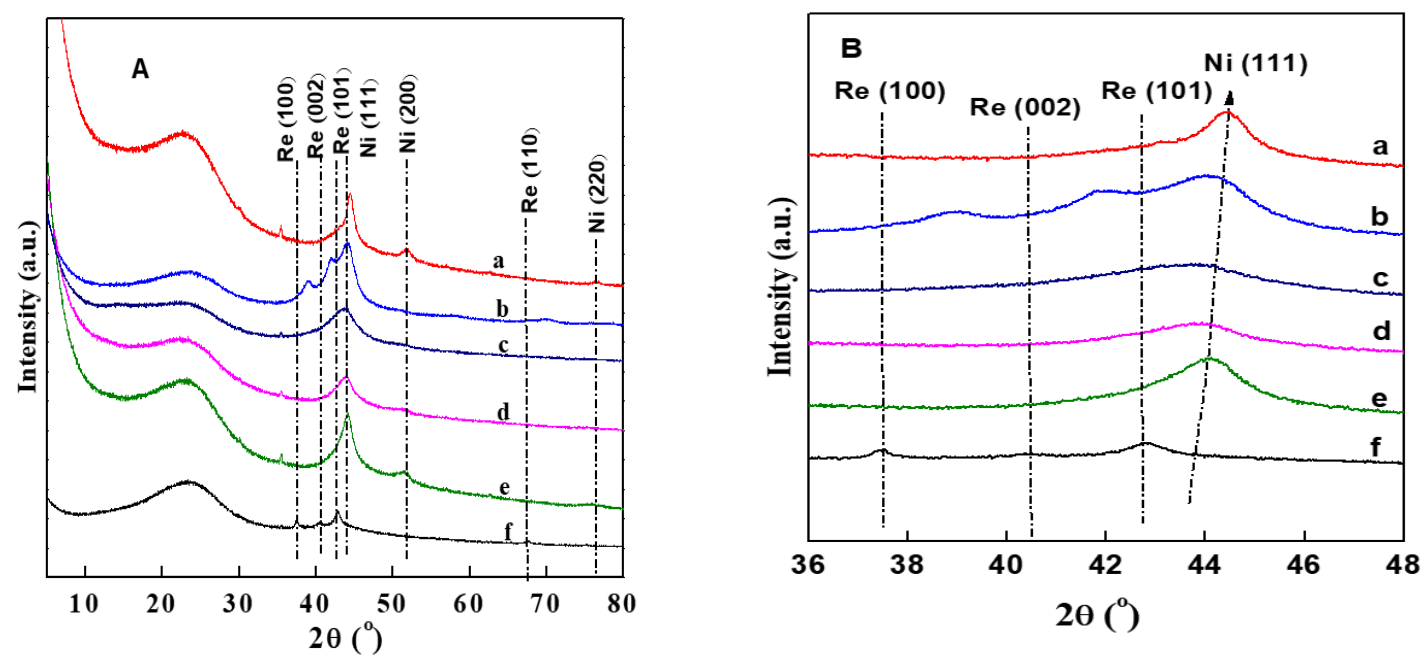

Figure 1. XRD patterns of (A) (a) Ni/activated carbon (AC), (b) $\mathrm{Ni}-\operatorname{Re} / \mathrm{AC}\left(\mathrm{n}_{\mathrm{Ni}}: \mathrm{n}_{\mathrm{Re}}=1: 1\right)$, (c) $\mathrm{Ni}-\operatorname{Re} / \mathrm{AC}\left(\mathrm{n}_{\mathrm{Ni}}: \mathrm{n}_{\mathrm{Re}}=2: 1\right),(\mathrm{d}) \mathrm{Ni}-\operatorname{Re} / \mathrm{AC}\left(\mathrm{n}_{\mathrm{Ni}}: \mathrm{n}_{\mathrm{Re}}=4: 1\right),(\mathrm{e}) \mathrm{Ni}-\operatorname{Re} / \mathrm{AC}\left(\mathrm{n}_{\mathrm{Ni}}: \mathrm{n}_{\mathrm{Re}}=10: 1\right)$, and (f) Re/AC. (B) Magnification of (A).

\subsection{TEM Results}

Figure 2 shows the three representative TEM and their high resolution TEM (HRTEM) images of the Ni/AC and Ni-Re catalysts, and the corresponding mean Ni particle sizes are listed in Table 1. It can be seen from Figure $2 \mathrm{~A}-\mathrm{C}$ that $\mathrm{Ni}$ particles or Re oxide particles were highly dispersed and uniformly distributed on the AC support surface.

Table 1. Sizes and XPS results of various catalyst.

\begin{tabular}{cccc}
\hline Entry & Catalyst & Ni Particle Size $(\mathbf{n m})^{\text {a }}$ & Ni Dispersion (CO/Ni) \\
\hline 1 & $\mathrm{Re} / \mathrm{AC}$ & $10.6 \pm 5.0$ & $\mathrm{Nd}^{\mathrm{b}}$ \\
2 & $\mathrm{Ni}-\mathrm{Re} / \mathrm{AC}\left(\mathrm{n}_{\mathrm{Ni}}: \mathrm{n}_{\mathrm{Re}}=1: 1\right)$ & $13.0 \pm 5.0$ & 0.080 \\
3 & $\mathrm{Ni}-\mathrm{Re} / \mathrm{AC}\left(\mathrm{n}_{\mathrm{Ni}}: \mathrm{n}_{\mathrm{Re}}=2: 1\right)$ & $15.1 \pm 6.1$ & 0.027 \\
4 & $\mathrm{Ni}-\mathrm{Re} / \mathrm{AC}\left(\mathrm{n}_{\mathrm{Ni}}: \mathrm{n}_{\mathrm{Re}}=4: 1\right)$ & $15.8 \pm 6.1$ & $/$ \\
5 & $\mathrm{Ni}-\mathrm{Re} / \mathrm{AC}\left(\mathrm{n}_{\mathrm{Ni}}: \mathrm{n}_{\mathrm{Re}}=\right.$ & $16.0 \pm 5.2$ & $/$ \\
6 & $10: 1)$ & $22.0 \pm 6.2$ & 0.020 \\
\hline
\end{tabular}

${ }^{\mathrm{a}}$ The Ni particle size was determined by TEM; ${ }^{\mathrm{b}}$ not detected.

Table 1 shows that a large particle size of ca. $22.0 \mathrm{~nm}$ was observed for the monometallic $\mathrm{Ni}$ /AC catalyst. After the introduction of Re, the particle size became smaller and more uniform compared to the Ni/AC catalyst. Moreover, with an increase of Re metal, the average particle size decreased from ca. $22.0 \mathrm{~nm}$ for $\mathrm{Ni} / \mathrm{AC}$ to ca. $13.0 \mathrm{~nm}$ for Ni-Re/AC $\left(\mathrm{n}_{\mathrm{Ni}}: \mathrm{n}_{\mathrm{Re}}=1: 1\right)$, showing that the addition of Re can effectively promote the dispersion of Ni metal nanoparticles (Table 1, Entries 2 through 6). The possible interpretation for the observation was that the introduction of Re was mostly like a baffle plate, which could prevent the further migration and agglomeration of $\mathrm{Ni}$ atoms or small particles from clustering into larger sized particles by the formation of alloy during the high temperature reduction process. HRTEM images were also taken to investigate the fine structures (Figure $2 \mathrm{~A}^{\prime}-\mathrm{C}^{\prime}$ ). For the monometallic Ni/AC catalyst, the resulting lattice fringe was approximately $0.205 \mathrm{~nm}$, which was attributed to that of $\mathrm{Ni}(111)$. After the incorporation of Re species, the lattice fringe was approximately $0.207 \mathrm{~nm}$, which was greater than that of $\mathrm{Ni}$ (111) for $\mathrm{Ni} / \mathrm{AC}$, but smaller than that of $\operatorname{Re}(101)(0.211 \mathrm{~nm})$ for $\mathrm{Re} / \mathrm{AC}$. The results were also consistent with the XRD results that the penetration of $\mathrm{Re}$ atoms into the $\mathrm{Ni}$ lattice during $\mathrm{H}_{2}$ high temperature reduction led to the expansion of the lattice, which further showed that the Ni-Re alloy was formed after the incorporation of Re species. The composition of the bimetallic Ni-Re/AC $\left(\mathrm{n}_{\mathrm{Ni}}: \mathrm{n}_{\mathrm{Re}}=1: 1\right)$ catalyst was further analyzed 
by the EDS mapping method (Figure 3). As can be seen, the Ni and Re elements were uniformly distributed on the AC support, which was also further indicative of the formation of Ni-Re alloy in these bimetallic catalysts.
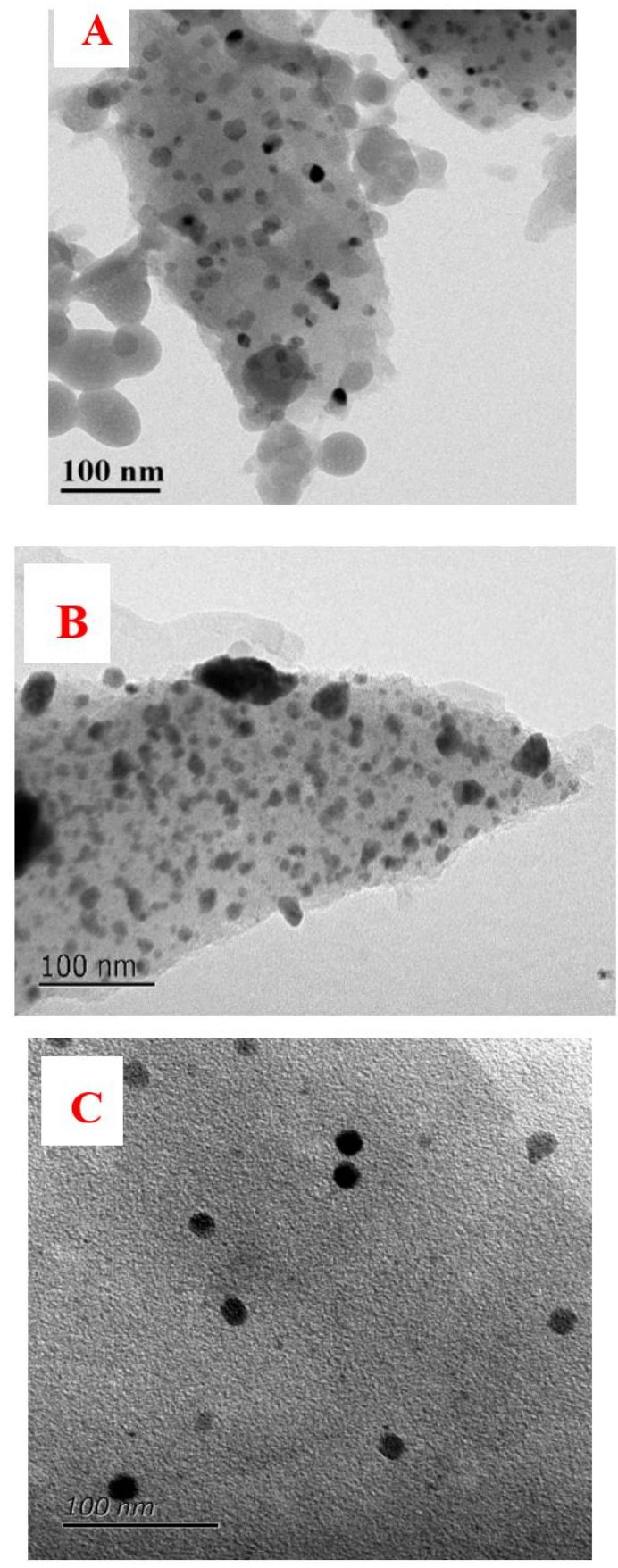
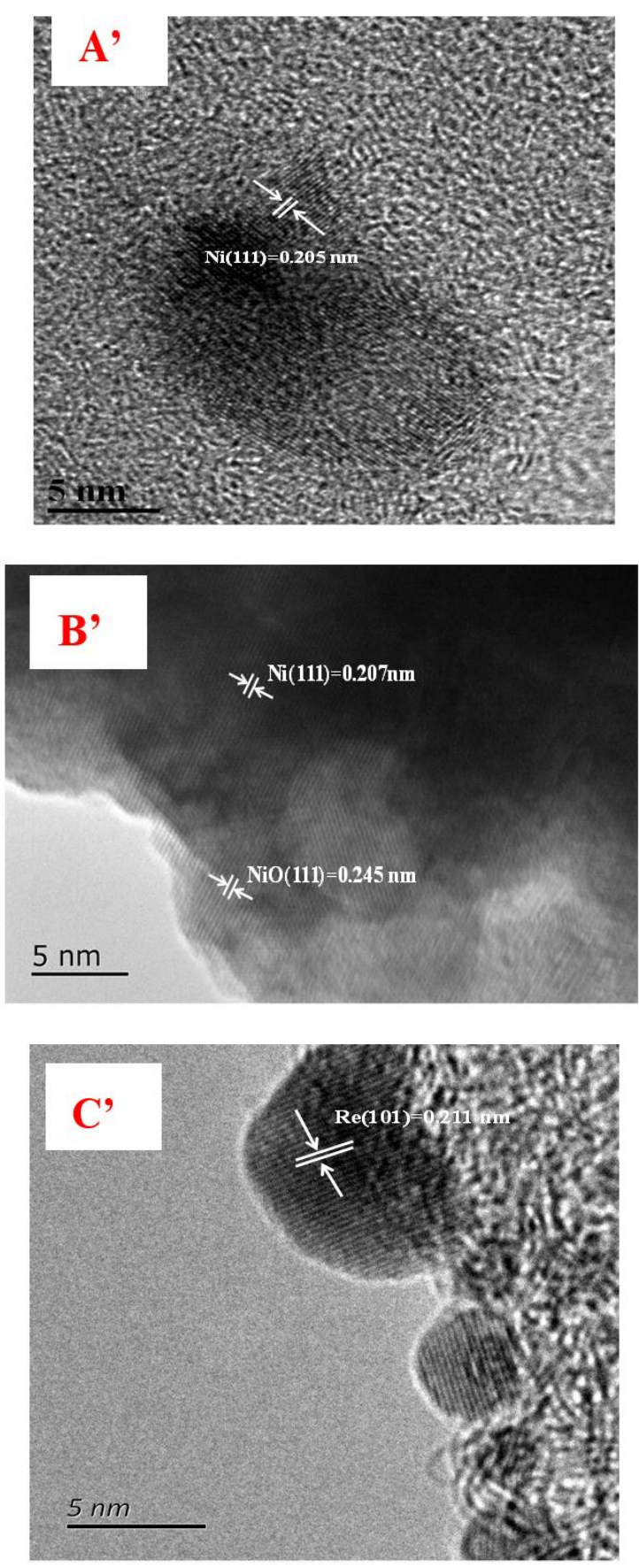

Figure 2. Three representative TEM images and their HRTEM images of Ni/AC $\left(\mathbf{A}, \mathbf{A}^{\prime}\right), \mathrm{Ni}-\mathrm{Re} / \mathrm{AC}$ $\left(\mathrm{n}_{\mathrm{Ni}}: \mathrm{n}_{\mathrm{Re}}=1: 1\right)\left(\mathbf{B}, \mathbf{B}^{\prime}\right)$, and $\operatorname{Re} / \mathrm{AC}\left(\mathbf{C}, \mathbf{C}^{\prime}\right)$. 

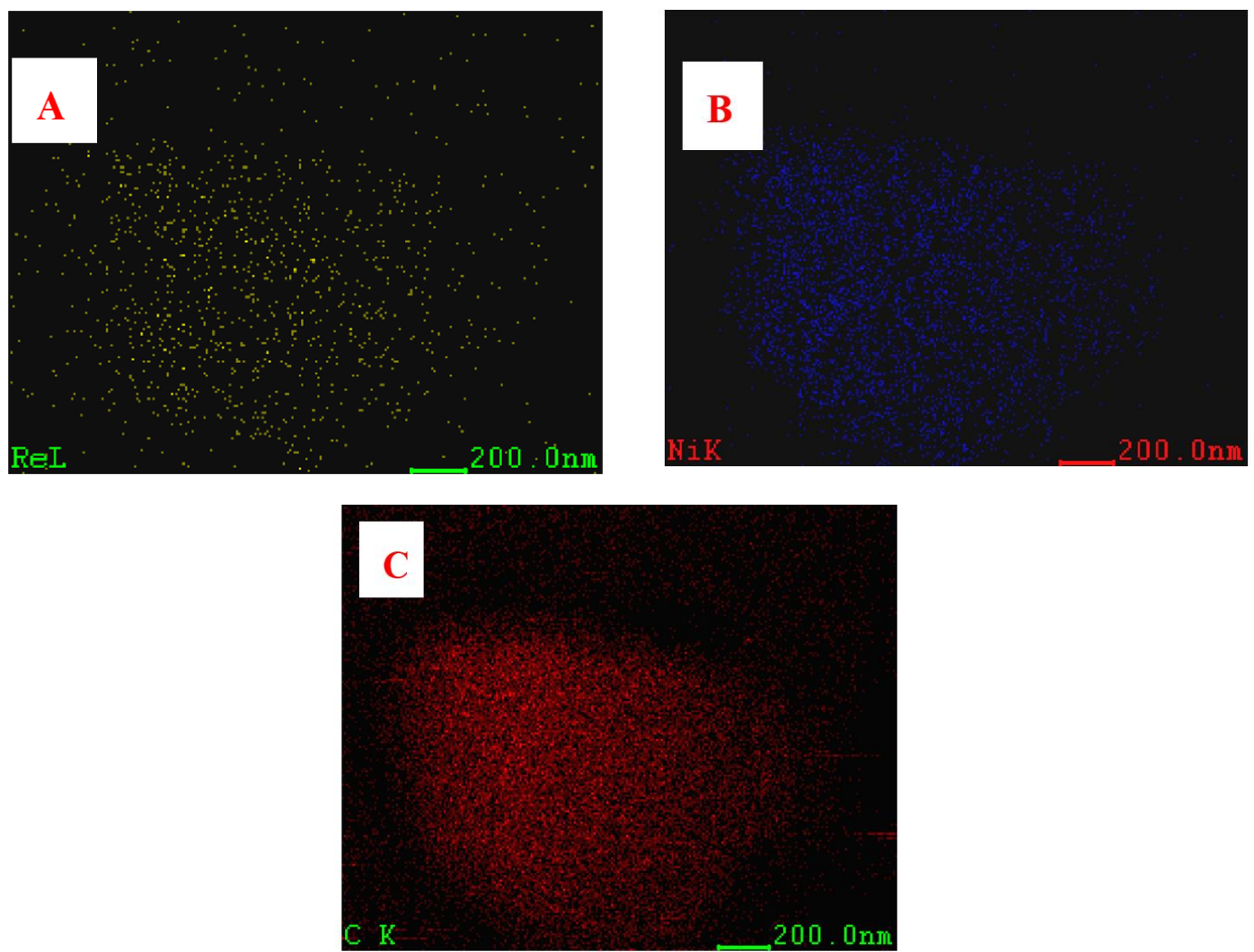

Figure 3. The elemental mapping of $5 \% \mathrm{Ni}-\mathrm{Re} / \mathrm{AC}\left(\mathrm{n}_{\mathrm{Ni}} \mathrm{n}_{\mathrm{Re}}=1: 1\right)$ catalyst: $(\mathbf{A}) \mathrm{Re} ;(\mathbf{B}) \mathrm{Ni}$; and $(\mathbf{C}) \mathrm{C}$.

\subsection{XPS Results}

XPS was used to analyze the surface elemental composition and valence state of the catalyst. The XPS results of $\mathrm{Ni} 2 \mathrm{p}$ regions for $\mathrm{Ni} / \mathrm{AC}$ and the bimetallic $\mathrm{Ni}$-Re catalysts are illustrated in Figure 4. As shown, the two samples exhibited similar Ni 2 p spectra. Besides a binding energy at approximately $862.5 \mathrm{eV}$ assigned to the shake-up satellite of $\mathrm{Ni} 2 \mathrm{p}_{3 / 2}$, two peaks at approximately 853.0 and approximately $856.0 \mathrm{eV}$ were observed, which were ascribed to $\mathrm{Ni}^{0}$ and $\mathrm{NiO}$ species $[38,44]$, respectively. Moreover, it was observed that the binding energy of $\mathrm{Ni}^{0}$ species shifted from $853.5 \mathrm{eV}$ for $\mathrm{Ni} / \mathrm{AC}$ to a higher binding energy of $854.0 \mathrm{eV}$ for $\mathrm{Ni}-\mathrm{Re} / \mathrm{AC}\left(\mathrm{n}_{\mathrm{Ni}}: \mathrm{n}_{\mathrm{Re}}=1: 1\right)$. Similar observations were also found for other Ni-Re samples (see Figure S2 in the Supplementary Material).
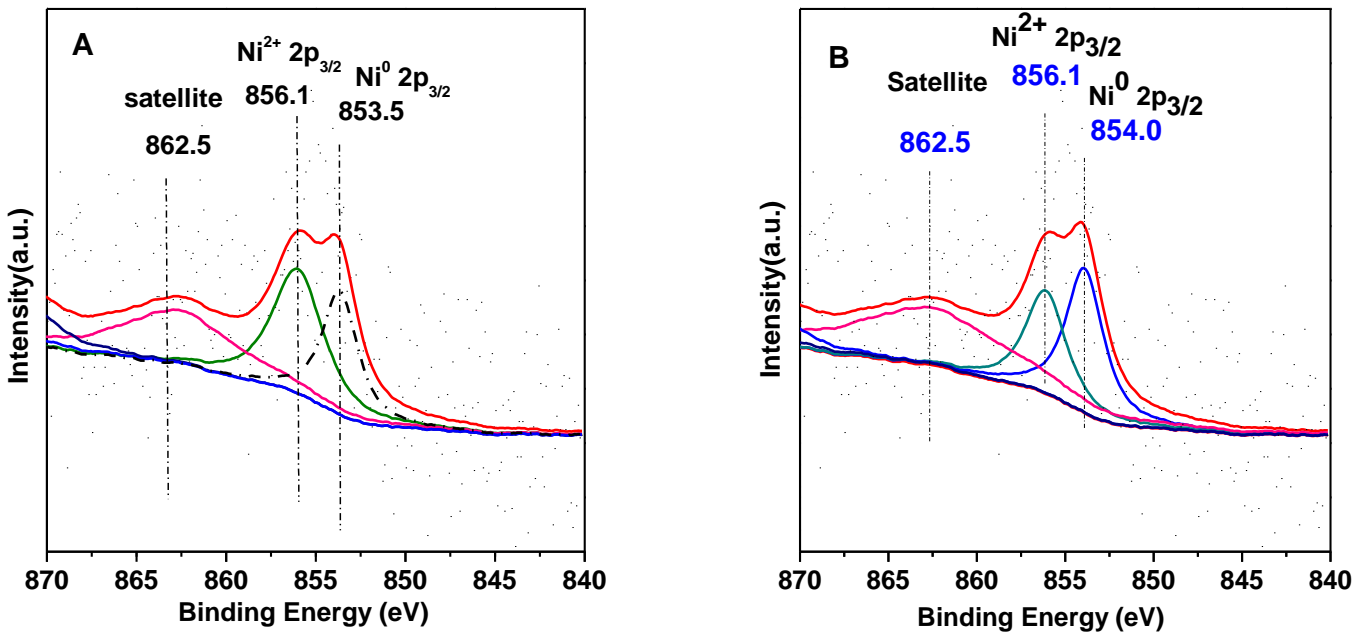

Figure 4. Two representative Ni 2p XPS of (A) $5 \% \mathrm{Ni} / \mathrm{AC}$ and (B) Ni-Re/AC( $\left.\mathrm{n}_{\mathrm{Ni}}: \mathrm{n}_{\mathrm{Re}}=1: 1\right)$. 
Figure 5 presents the XPS spectra of the Re 4 f region for $\operatorname{Re} / A C$ and $\mathrm{Ni}-\operatorname{Re} / \mathrm{AC}\left(\mathrm{n}_{\mathrm{Ni}}: \mathrm{n}_{\mathrm{Re}}=1: 1\right)$. For the two samples, five deconvoluted peaks appeared at 40.8, 41.9, 43.2, 45.0, and $45.8 \mathrm{eV}$, which were assigned to the $4 f_{7 / 2}$ of $\operatorname{Re}^{0}, \operatorname{Re}^{3+}, \operatorname{Re}^{4+}, \operatorname{Re}^{6+}$, and $\operatorname{Re}^{7+}$ species [38,44], respectively. Similar phenomena for Re 4f spectra were also found for other Ni-Re samples (See Figure S3 in the Supplementary Material). The presence of different oxidation states was attributed to the strong oxophilicity of Re. It should be noted that partial oxidation of Re cannot be avoided upon exposure to air. Furthermore, it was observed that the peak intensities of $\operatorname{Re}^{0}$ together with $\operatorname{Re}^{3+}$ and $\operatorname{Re}^{4+}$ species of $\mathrm{Ni}-\operatorname{Re} / \mathrm{AC}\left(\mathrm{n}_{\mathrm{Ni}}: \mathrm{n}_{\mathrm{Re}}=1: 1\right)$ were higher than those of Re/AC, albeit the two samples contained the same Re loading, while the situation was converse for $\operatorname{Re}^{6+}$ and $\mathrm{Re}^{7+}$ with high valence states for the two samples. The results clearly suggested that the Re species were reduced readily to lower valence states or low valence state species $\left(\operatorname{Re}^{0}\right.$, etc.) were more difficult to oxidize due to the formation of the Ni-Re alloy.
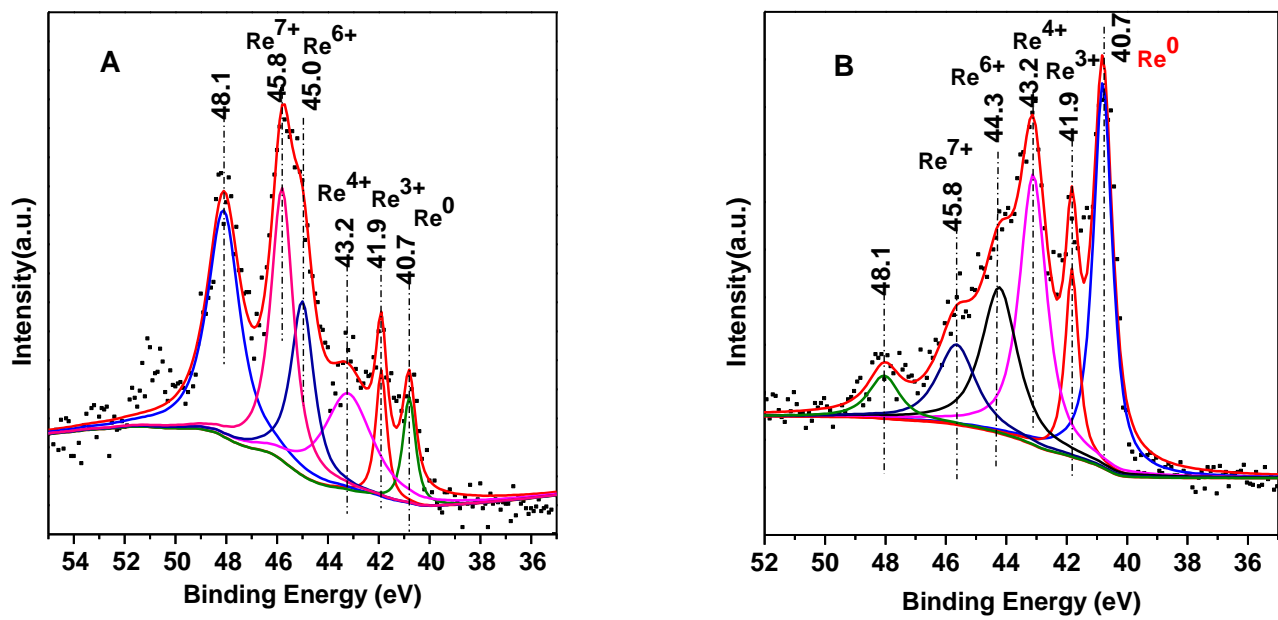

Figure 5. Two representative Re $4 \mathrm{f}$ XPS of (A) $15.8 \% \operatorname{Re} / \mathrm{AC}$ and (B) Ni-Re/AC $\left(\mathrm{n}_{\mathrm{Ni}}: \mathrm{n}_{\mathrm{Re}}=1: 1\right)$.

\subsection{CO Chemisorption}

The amount of surface active $\mathrm{Ni}$ sites was determined by $\mathrm{CO}$ chemisorption. For the $\mathrm{Re} / \mathrm{AC}$ catalyst, the amount of adsorbed $\mathrm{CO}$ could be neglected, suggesting that Re species did not adsorb $\mathrm{CO}$ at a low temperature. Thus, $\mathrm{CO}$ adsorption on the bimetallic Ni-Re catalysts may be regarded as only related to the active $\mathrm{Ni}$ sites. As shown in Table 1, CO/Ni increased from 0.02 for Ni/AC to 0.08 for $\mathrm{Ni}-\mathrm{Re} / \mathrm{AC}\left(\mathrm{n}_{\mathrm{Ni}}: \mathrm{n}_{\mathrm{Re}}=1: 1\right)$ and 0.027 for $\mathrm{Ni}-\mathrm{Re} / \mathrm{AC}\left(\mathrm{n}_{\mathrm{Ni}}: \mathrm{n}_{\mathrm{Re}}=2: 1\right)$. For Re/AC, no CO adsorption was detected. These results also showed that the incorporation of Re species markedly enhanced the formation of surface active Ni sites.

\subsection{Catalytic Performances}

The effect of reaction temperature on the conversion of xylose and the yield of xylitol was investigated (Table 2). It can be inferred from Table 2 that a xylitol yield of $77.6 \%$ with a xylose conversion of $79.0 \%$ was obtained over $\mathrm{Ni}-\mathrm{Re} / \mathrm{AC}\left(\mathrm{n}_{\mathrm{Ni}}: \mathrm{n}_{\mathrm{Re}}=1: 1\right)$ at $120{ }^{\circ} \mathrm{C}$ for $2 \mathrm{~h}$. As the reaction temperature was greater than $140{ }^{\circ} \mathrm{C}$, complete conversion of xylose was achieved, but the xylitol yield was reduced from $95.6 \%$ at $140{ }^{\circ} \mathrm{C}$ to $64.8 \%$ at $200{ }^{\circ} \mathrm{C}$ (Table 2, Entries 4 and 7). This was due to the fact that high temperature led to the formation of byproducts including furfural produced from xylose dehydration, even ethylene glycol (EG), and 1,2-propanediol formed from xylitol hydrogenolysis at $200{ }^{\circ} \mathrm{C}$.

The influence of the reaction time on the hydrogenation of xylose to xylitol was also investigated. When the reaction time was $0.5 \mathrm{~h}$, a xylitol yield of $57.2 \%$ at a xylose conversion of $59 \%$ was afforded over Ni-Re/AC $\left(\mathrm{n}_{\mathrm{Ni}}: \mathrm{n}_{\mathrm{Re}}=1: 1\right)$ at $140{ }^{\circ} \mathrm{C}$. A high yield up to $98.0 \%$ was achieved at $140{ }^{\circ} \mathrm{C}$ for $1 \mathrm{~h}$. As the reaction time was extended to $2 \mathrm{~h}$, the xylitol yield slightly dropped to $95.6 \%$ because of the occurrence of side reactions such as xylose dehydration. 
Table 2. Effect of different reaction conditions on the hydrogenation of xylose to xylitol ${ }^{\text {a }}$.

\begin{tabular}{ccccc}
\hline Entry & Temperature $\left({ }^{\circ} \mathbf{C}\right)$ & Time (h) & Xylose Conversion (\%) & Xylitol Yield (\%) \\
\hline 1 & 120 & 2.0 & 79 & 77.6 \\
2 & 140 & 0.5 & 59 & 57.2 \\
3 & 140 & 1.0 & 99 & 98.0 \\
4 & 140 & 2.0 & 99 & 95.6 \\
5 & 160 & 2.0 & 99 & 93.0 \\
6 & 180 & 2.0 & 99 & 85.8 \\
7 & 200 & 2.0 & 99 & 64.8 \\
\hline
\end{tabular}

${ }^{a}$ Reaction conditions: $1.0 \mathrm{~g}$ xylose, $20 \mathrm{~mL} \mathrm{H}_{2} \mathrm{O}, 0.1 \mathrm{~g} \mathrm{Ni}-\mathrm{Re} / \mathrm{AC}\left(\mathrm{n}_{\mathrm{Ni}}: \mathrm{n}_{\mathrm{Re}}=1: 1\right)$ catalyst.

Figure 6 shows the effect of the Ni/Re ratio on the hydrogenation of xylose to xylitol over various catalysts at $140{ }^{\circ} \mathrm{C}$ for $1 \mathrm{~h}$. Ni/AC afforded a xylitol yield of $62.7 \%$ with a xylose conversion of $70 \%$. As the Re loading increased, complete xylose conversion was achieved over four Ni-Re bimetallic catalysts, suggesting that the incorporation of Re could obviously promote the xylose conversion, i.e., the formation of alloy favored the conversion of xylose and enhanced the hydrogenation activity. Additionally, an increase in Re content resulted in an increase in xylitol yield from $92.5 \%$ for Ni-Re/AC $\left(\mathrm{n}_{\mathrm{Ni}}: \mathrm{n}_{\mathrm{Re}}=10: 1\right)$ to $98 \%$ for $\mathrm{Ni}-\mathrm{Re} / \mathrm{AC}\left(\mathrm{n}_{\mathrm{Ni}}: \mathrm{n}_{\mathrm{Re}}=1: 1\right)$. The possible explanation is that as the $\operatorname{Re}$ loading increased, the particle size also decreased, resulting in approximately $16.0 \mathrm{~nm}$ for $\mathrm{Ni}-\mathrm{Re} / \mathrm{AC}$ $\left(\mathrm{n}_{\mathrm{Ni}}: \mathrm{n}_{\mathrm{Re}}=10: 1\right)$ to approximately $13.0 \mathrm{~nm}$ for $\mathrm{Ni}-\mathrm{Re} / \mathrm{AC}\left(\mathrm{n}_{\mathrm{Ni}}: \mathrm{n}_{\mathrm{Re}}=1: 1\right)$ because smaller particle sizes afforded higher catalytic activity. It should be noted that the monometallic Re/AC catalyst did not show any hydrogenation activity of xylose under identical reaction conditions.

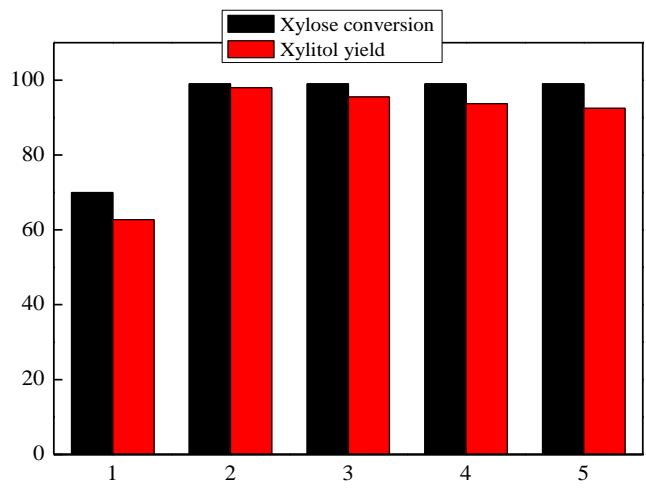

Figure 6. Effect of the $\mathrm{Ni} / \mathrm{Re}$ ratio on the conversion of xylose and the yield of xylitol over various catalysts: (1) Ni/AC; (2) Ni-Re/AC ( $\left.\mathrm{n}_{\mathrm{Ni}}: \mathrm{n}_{\mathrm{Re}}=1: 1\right)$; (3) Ni-Re/AC ( $\left.\mathrm{n}_{\mathrm{Ni}}: \mathrm{n}_{\mathrm{Re}}=2: 1\right)$; (4) Ni-Re/AC $\left(\mathrm{n}_{\mathrm{Ni}}: \mathrm{n}_{\mathrm{Re}}=4: 1\right) ;(5) \mathrm{Ni}-\mathrm{Re} / \mathrm{AC}\left(\mathrm{n}_{\mathrm{Ni}}: \mathrm{n}_{\mathrm{Re}}=10: 1\right)$. Reaction conditions: $1.0 \mathrm{~g}$ xylose, $20.0 \mathrm{~mL}$ deionized water, $0.1 \mathrm{~g}$ catalyst, $2 \mathrm{MPa}$ of $\mathrm{H}_{2}$, and $140{ }^{\circ} \mathrm{C}$ for $1 \mathrm{~h}$.

Figure 7 displays the impact of xylose concentration on the hydrogenation of xylose to xylitol on $\mathrm{Ni}-\mathrm{Re} / \mathrm{AC}\left(\mathrm{n}_{\mathrm{Ni}}: \mathrm{n}_{\mathrm{Re}}=1: 1\right)$. When the xylose concentration was $50 \mathrm{mg} / \mathrm{mL}$, a xylitol yield of $96 \%$ was obtained. As the xylose concentration further increased, the xylitol yield was only slightly reduced to $93 \%$ for a $100 \mathrm{mg} / \mathrm{mL}$ concentration and $92 \%$ for a $200 \mathrm{mg} / \mathrm{mL}$ concentration. This also indicated that the catalyst still kept its high catalytic performances even as the xylose concentration was close to $20 \%$.

Table 3 summarizes the experimental conditions and the catalytic results of the hydrogenation of xylose to xylitol. Most of the noble metal catalysts (i.e., Pd, Ru, Rh) and non-noble metal catalysts (i.e., Ni) were active for the xylose hydrogenation. A comparison of the catalytic properties reported in the literature is very complicated because of various experimental conditions. It can be inferred from Table 3 that the Ru/AC catalyst gave a high selectivity up to 98.7\% toward xylitol. Moreover, it was found that $\mathrm{AC}$ was an excellent support because $\mathrm{Ru} / \mathrm{AC}$ showed a superior catalytic performance as compared to other supported $\mathrm{Ru}$ based catalysts. The Ru based catalysts were demonstrated to have a good stability in catalyst recycling experiments. The disadvantage of the Ru based catalysts was that 
$\mathrm{Ru}$ metal was more expensive than $\mathrm{Ni}$ metal. Ni-Re/AC used in this work exhibited a comparable performance to that of Raney $\mathrm{Ni}$ or $\mathrm{Ru} / \mathrm{TiO}_{2}$. The drawback of $\mathrm{Ni}$ based catalysts was that the surface $\mathrm{Ni}$ active sites were prone to leaching.

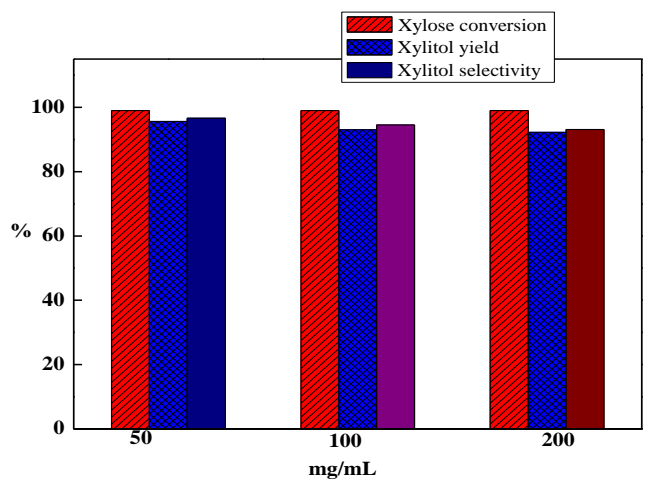

Figure 7. Effect of xylose concentration on the conversion of xylose, the xylitol yield, and the selectivity toward xylitol over Ni-Re/AC $\left(\mathrm{n}_{\mathrm{Ni}}: \mathrm{n}_{\mathrm{Re}}=1: 1\right)$. Reaction conditions: $20 \mathrm{~mL}$ deionized water, $0.1 \mathrm{~g}$ catalyst, $2 \mathrm{MPa}$ of $\mathrm{H}_{2}$, and $140{ }^{\circ} \mathrm{C}$ for $1 \mathrm{~h}$.

Table 3. Summary of the catalytic hydrogenation of xylose to xylitol with various catalysts.

\begin{tabular}{|c|c|c|c|c|c|c|}
\hline Catalyst & Tem. $\left({ }^{\circ} \mathrm{C}\right)$ & Time (h) & $\mathrm{H}_{2}$ pre. (bar) & Conversion $(\%)$ & Selectivity (\%) & Ref. \\
\hline $\mathrm{Ru} / \mathrm{AC}$ & 110 & 1.5 & 50 & 100 & 98.7 & [35] \\
\hline $\mathrm{Rh} /$ perovskite & 100 & 2.0 & 25 & 100 & 51.0 & [32] \\
\hline $\mathrm{Ru} /$ polymer & 120 & 2.0 & 55 & 99.8 & 94.1 & [34] \\
\hline $\mathrm{Ru} / \mathrm{TiO}_{2}$ & 120 & 1.0 & 20 & 100 & 98.0 & [36] \\
\hline $\mathrm{Ru} / \mathrm{Y}^{2}$ & 120 & 1.0 & 55 & 62 & 98.0 & [29] \\
\hline $\mathrm{NdCeAl}_{0.162} \mathrm{Ni}_{0.838}$ & 100 & 2.0 & / & 20 & 50.0 & [36] \\
\hline Raney Ni & 120 & 2.0 & 55 & 96.9 & 96.7 & [14] \\
\hline $\mathrm{Ni}-\mathrm{Re} / \mathrm{AC}$ & 140 & 1.0 & 20 & 99 & 98 & This work \\
\hline
\end{tabular}

\subsection{Hemicellulosic Hydrolysate Hydrogenation Reaction}

The hemicellulosic hydrolysate was also used for the hydrogenation of xylose into xylitol. The authors employed the optimal reaction conditions that were obtained by optimizing the reaction conditions using commercial xylose as the model substrate. The obtained hydrolysate generated from the hydrolysis reaction of hemicellulose of Camellia oleifera shell was used for xylose hydrogenation reaction at $140{ }^{\circ} \mathrm{C}$ for $1 \mathrm{~h}$. A high xylose yield of $88.2 \%$ with a xylose conversion of $93.2 \%$ was achieved under the optimized reaction conditions. An inferior yield of xylose using the hydrolysate as the starting material was obtained in comparison with using commercial xylose because the hydrolysate contained a higher concentration of metal impurity ions or other trace impurities, such as lignin fragments, which led to a reduction in the hydrogenation activity of xylose.

\subsection{The Recycling Experiment}

The long term stability of heterogeneous catalyst is very important for catalytic reactions. Thus, the stability of the catalysts (Ni/AC and (b) $\mathrm{Ni}-\mathrm{Re} / \mathrm{AC}\left(\mathrm{n}_{\mathrm{Ni}}: \mathrm{n}_{\mathrm{Re}}=1: 1\right)$ ) catalysts) in the hydrogenation reaction of xylose was evaluated. The recovered catalysts were washed and dried before their reuse. As shown in Figure 8, for the second run, the xylose conversion and xylitol yield were substantially reduced, but the xylitol selectivity was not changed, showing that the two catalysts were very prone to deactivation. According to the literature results previously mentioned in the Introduction, the authors prospected that the catalyst deactivation was owed to the deposition of organic compounds on the active Ni sites. Thus, a regeneration procedure was employed under $1 \% \mathrm{H}_{2}$ flow at $500{ }^{\circ} \mathrm{C}$ for $2 \mathrm{~h}$. After the regeneration, the third recycle was conducted. The result showed that 
the catalyst's activity was markedly recovered, but the xylose conversion and xylitol yield were still lower than those obtained from the fresh catalyst. The deactivation reason was further analyzed by ICP-OES, and the results revealed that the Ni leaching for Ni/AC and Ni-Re/AC $\left(\mathrm{n}_{\mathrm{Ni}}: \mathrm{n}_{\mathrm{Re}}=1: 1\right)$ took place after the first run. However, the leaching percentage of $\mathrm{Ni}$ for $\mathrm{Ni}-\mathrm{Re} / \mathrm{AC}\left(\mathrm{n}_{\mathrm{Ni}}: \mathrm{n}_{\mathrm{Re}}=1: 1\right)($ ca. $2.1 \%)$ was approximately one fifth that of Ni/AC (ca. 10.2\%), clearly demonstrating that the presence of Re evidently enhanced the stability and decreased the Ni leaching. The other factors, such as $\mathrm{Ni}$ nanoparticle sintering and poisoning by strongly absorbed degradation products, probably further led to deactivation of the catalyst. Thus, albeit that the Re can substantially improve the catalyst stability and the catalytic performances, further effort needs to be undertaken, which includes the choice of other supports with strong metal-support interaction or other transition metals that may enhance the stability of the Ni based catalyst.
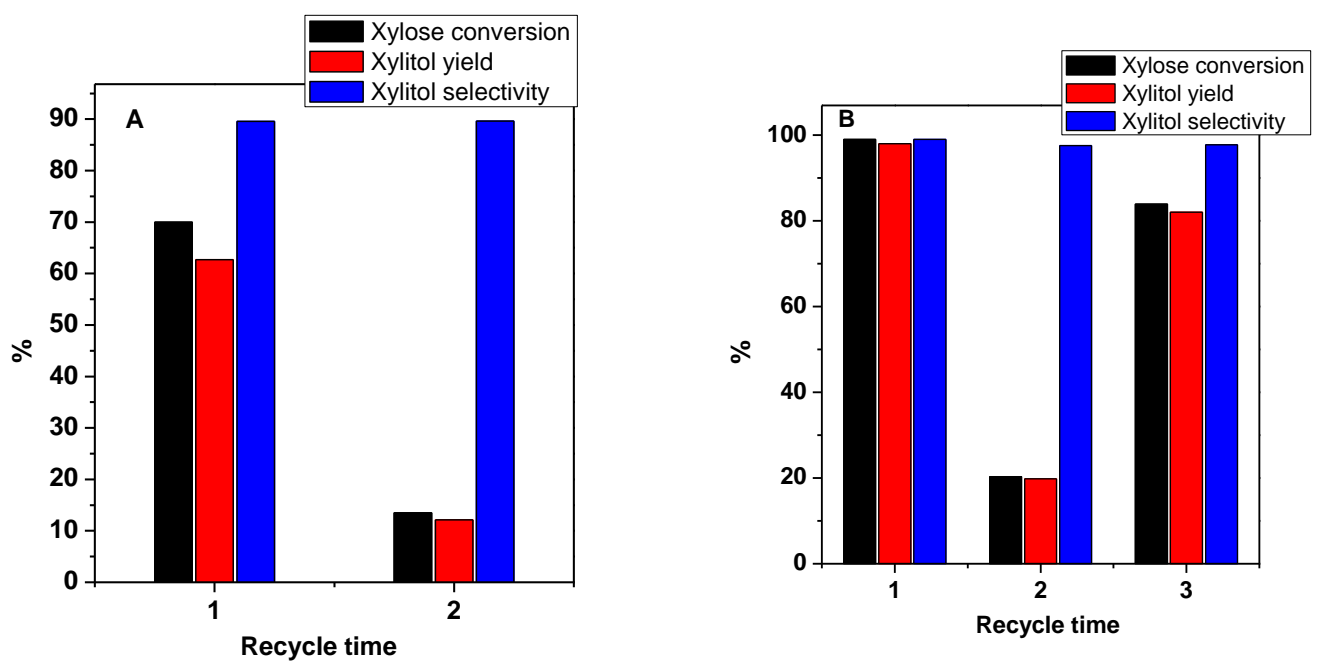

Figure 8. Reusability of (A) Ni/AC and (B) Ni-Re/AC $\left(\mathrm{n}_{\mathrm{Ni}}: \mathrm{n}_{\mathrm{Re}}=1: 1\right)$ catalysts. Reaction conditions: $20 \mathrm{~mL}$ deionized water, $0.1 \mathrm{~g}$ catalyst, $2 \mathrm{MPa}$ of $\mathrm{H}_{2}$, and $140{ }^{\circ} \mathrm{C}$ for $1 \mathrm{~h}$.

\section{Conclusions}

A series of $\mathrm{Ni}-\mathrm{Re} / \mathrm{AC}$ bimetallic catalysts with different $\mathrm{Ni} / \mathrm{Re}$ ratios was developed and used for the hydrogenation of xylose and the xylose containing hydrolysate into xylitol. The bimetallic $\mathrm{Ni}$-Re/AC catalysts exhibited excellent catalytic performances in the hydrogenation of xylose and the hydrolysate from Camellia oleifera shell. Ni-Re/AC $\left(\mathrm{n}_{\mathrm{Ni}}: \mathrm{n}_{\mathrm{Re}}=1: 1\right)$ with $5 \mathrm{wt} \%$ Ni loading afforded a xylitol yield as high as $98 \%$ at $140{ }^{\circ} \mathrm{C}$ for $1 \mathrm{~h}$, which was attributable to the synergistic effect between $\mathrm{Ni}$ and $\mathrm{Re}$, as well as small Ni particle sizes. The reusability experimental results indicated that the $\mathrm{Ni}$ leaching occurred over both monometallic $\mathrm{Ni}$ and bimetallic Ni-Re catalyst, but the incorporation of Re remarkably enhanced the catalyst stability and decreased the Ni leaching level during the hydrogenation reaction.

Supplementary Materials: The following are available online at http://www.mdpi.com/2079-4991/10/1/73/s1. Figure S1: TEM images and their corresponding size distributions of $\left(A, A^{\prime}\right) \mathrm{Ni}-\operatorname{Re} / \mathrm{AC}\left(\mathrm{n}_{\mathrm{Ni}}: \mathrm{n}_{\mathrm{Re}}=10: 1\right)\left(B, B^{\prime}\right)$ $\mathrm{Ni}-\operatorname{Re} / \mathrm{AC}\left(\mathrm{n}_{\mathrm{Ni}}: \mathrm{n}_{\mathrm{Re}}=4: 1\right)\left(\mathrm{C}, \mathrm{C}^{\prime}\right) \mathrm{Ni}-\operatorname{Re} / \mathrm{AC}\left(\mathrm{n}_{\mathrm{Ni}}: \mathrm{n}_{\mathrm{Re}}=2: 1\right)$; Figure S2: Ni $2 \mathrm{p}$ XPS of $(\mathrm{A}) \mathrm{Ni}-\operatorname{Re} / \mathrm{AC}\left(\mathrm{n}_{\mathrm{Ni}}: \mathrm{n}_{\mathrm{Re}}=10: 1\right)(B)$ $\mathrm{Ni}-\operatorname{Re} / \mathrm{AC}\left(\mathrm{n}_{\mathrm{Ni}}: \mathrm{n}_{\mathrm{Re}}=4: 1\right)$ and $(C) \mathrm{Ni}-\operatorname{Re} / \mathrm{AC}\left(\mathrm{n}_{\mathrm{Ni}}: \mathrm{n}_{\mathrm{Re}}=2: 1\right)$; Figure S3: Re $4 \mathrm{f}$ XPS of $(\mathrm{A}) \mathrm{Ni}-\operatorname{Re} / \mathrm{AC}\left(\mathrm{n}_{\mathrm{Ni}}: \mathrm{n}_{\mathrm{Re}}=10: 1\right)(B)$ $\mathrm{Ni}-\operatorname{Re} / \mathrm{AC}\left(\mathrm{n}_{\mathrm{Ni}}: \mathrm{n}_{\mathrm{Re}}=4: 1\right)$ and $(C) \mathrm{Ni}-\operatorname{Re} / \mathrm{AC}\left(\mathrm{n}_{\mathrm{Ni}}: \mathrm{n}_{\mathrm{Re}}=2: 1\right)$; Table S1: The hydrolysis reaction of Camellia oleifera shell.

Author Contributions: Conceptualization, H.X. and L.Y.; methodology, H.H. and L.Z.; validation, L.Z. and S.Z.; investigation, L.Z.; writing, original draft preparation, H.X.; writing, review and editing, L.Y.; project administration, L.Y. All authors have read and agreed to the published version of the manuscript.

Funding: This work was financially supported by the National Key R\&D Program of China (Grant No. 2017YFD0601006) and the Natural Science Foundation of Jiangsu Province (Grant No. BK20171452). This work was also financially supported by the Postgraduate Research \& Practice Innovation Program of Jiangsu Province.

Conflicts of Interest: The authors declare no conflict of interest. 


\section{References}

1. Li, C.; Zhao, X.; Wang, A.; Huber, G.W.; Zhang, T. Catalytic Transformation of Lignin for the Production of Chemicals and Fuels. Chem. Rev. 2015, 115, 11559-11624. [CrossRef] [PubMed]

2. Morgan, H.M., Jr.; Bu, Q.; Liang, J.; Liu, Y.; Mao, H.; Shi, A.; Lei, H.; Ruan, R. A review of catalytic microwave pyrolysis of lignocellulosic biomass for value-added fuel and chemicals. Bioresour. Technol. 2017, 230, 112-121. [CrossRef] [PubMed]

3. Zhang, Z.; Song, J.; Han, B. Catalytic Transformation of Lignocellulose into Chemicals and Fuel Products in Ionic Liquids. Chem. Rev. 2017, 117, 6834-6880. [CrossRef] [PubMed]

4. Chen, S.; Wojcieszak, R.; Dumeignil, F.; Marceau, E.; Royer, S. How Catalysts and Experimental Conditions Determine the Selective Hydroconversion of Furfural and 5-Hydroxymethylfurfural. Chem. Rev. 2018, 118, 11023-11117. [CrossRef]

5. Hong, M.; Min, J.; Wang, S. Metal-Free Epoxidation of Internal and Terminal Alkenes with tert-Butyl Hydroperoxide/Isobutyraldehyde/Oxygen System. Chemistryselect 2018, 3, 4818-4821. [CrossRef]

6. Mika, L.T.; Csefalvay, E.; Nemeth, A. Catalytic Conversion of Carbohydrates to Initial Platform Chemicals: Chemistry and Sustainability. Chem. Rev. 2018, 118, 505-613. [CrossRef]

7. Xiang, Z.; Liang, J.; Morgan, H.M., Jr.; Liu, Y.; Mao, H.; Bu, Q. Thermal behavior and kinetic study for co-pyrolysis of lignocellulosic biomass with polyethylene over Cobalt modified ZSM-5 catalyst by thermogravimetric analysis. Bioresour. Technol. 2018, 247, 804-811. [CrossRef]

8. Xia, H.; Xu, S.; Hu, H.; An, J.; Li, C. Efficient conversion of 5-hydroxymethylfurfural to high-value chemicals by chemo- and bio-catalysis. RSC Adv. 2018, 8, 30875-30886. [CrossRef]

9. Zhang, Z.; Huber, G.W. Catalytic oxidation of carbohydrates into organic acids and furan chemicals. Chem. Soc. Rev. 2018, 47, 1351-1390. [CrossRef]

10. Chen, S.; Zhou, G.L.; Miao, C.X. Green and renewable bio-diesel produce from oil hydrodeoxygenation: Strategies for catalyst development and mechanism. Renew. Sustain. Energy Rev. 2019, 101, 568-589. [CrossRef]

11. Sun, G.; An, J.; Hu, H.; Li, C.; Zuo, S.; Xia, H. Green catalytic synthesis of 5-methylfurfural by selective hydrogenolysis of 5-hydroxymethylfurfural over size-controlled Pd nanoparticle catalysts. Catal. Sci. Technol. 2019, 9, 1238-1244. [CrossRef]

12. Mikkola, J.P.; Salmi, T. Three-phase catalytic hydrogenation of xylose to xylitol prolonging the catalyst activity by means of on-line ultrasonic treatment. Catal. Today 2001, 64, 271-277. [CrossRef]

13. Mikkola, J.P.; Salmi, T.; Villela, A.; Vainio, H.; Maki-Arvela, P.; Kalantar, A.; Ollonqvist, T.; Vayrynen, J.; Sjoholm, R. Hydrogenation of xylose to xylitol on sponge nickel catalyst-A study of the process and catalyst deactivation kinetics. Braz. J. Chem. Eng. 2003, 20, 263-271. [CrossRef]

14. Yadav, M.; Mishra, D.K.; Hwang, J.-S. Catalytic hydrogenation of xylose to xylitol using ruthenium catalyst on $\mathrm{NiO}$ modified $\mathrm{TiO}_{2}$ support. Appl. Catal. A Gen. 2012, 425, 110-116. [CrossRef]

15. Hilpmann, G.; Steudler, S.; Ayubi, M.M.; Pospiech, A.; Walther, T.; Bley, T.; Lange, R. Combining Chemical and Biological Catalysis for the Conversion of Hemicelluloses: Hydrolytic Hydrogenation of Xylan to Xylitol. Catal. Lett. 2019, 149, 69-76. [CrossRef]

16. Tangale, N.P.; Niphadkar, P.S.; Joshi, P.N.; Dhepe, P.L. Hierarchical K/LTL zeolite as solid base for aqueous phase hydrogenation of xylose to xylitol. Micropor. Mesopor. Mater. 2019, 278, 70-80. [CrossRef]

17. Huang, C.; Chu, Q.; Xie, Y.; Li, X.; Jin, Y.; Min, D.; Yong, Q. Effect of Kraft Pulping Pretreatment on the Chemical Composition, Enzymatic Digestibility, and Sugar Release of Moso Bamboo Residues. Bioresources 2015, 10, 240-255. [CrossRef]

18. Li, X.; Gu, X.; Lai, C.; Ouyang, J.; Yong, Q. Production of Fumaric Acid by Rhizopus oryzae in Simultaneous Saccharification and Fermentation using Xylo-Oligosaccharides Manufacturing Waste Residue. Bioresources 2016, 11, 8831-8843. [CrossRef]

19. Ren, J.; Liu, L.; Xu, Q.; Li, X.; Yong, Q.; Ouyang, J. Comparative Evaluation of Magnesium Bisulfite Pretreatment under Different pH Values for Enzymatic Hydrolysis of Corn Stover. Bioresources 2016, 11, 7258-7270. [CrossRef]

20. Lai, C.; Li, X.; Zhu, J.; Yu, S.; Yong, Q. Detoxification of Steam-Exploded Corn Stover Prehydrolyzate with Organobentonite Enhances Ethanol Fermentation by Pichia stipites. Bioresources 2016, 11, 1905-1918. [CrossRef] 
21. Huang, C.; Huang, C.; Lai, C.; Wu, X.; Huang, Y.; He, J.; Li, X.; Yong, Q. Strategy to Utilize the High Ash Content Biomass Feedstock for Fermentable Sugars. Bioresources 2017, 12, 8306-8319.

22. Zhang, T.; Kumar, R.; Tsai, Y.-D.; Elander, R.T.; Wyman, C.E. Xylose yields and relationship to combined severity for dilute acid post- hydrolysis of xylooligomers from hydrothermal pretreatment of corn stover. Green Chem. 2015, 17, 394-403. [CrossRef]

23. Ma, W.; Li, K.; Guo, H.; Yan, L.; Dai, Y.; Luo, X.; Yao, Y. Fabrication of porous carbon microspheres with numerous spherical microstructures directly from waste Camellia oleifera shells and their application in sustained-release of 5-fluorouracil. Micropor. Mesopor. Mater. 2017, 250, 195-202. [CrossRef]

24. Fan, F.; Zheng, Y.; Huang, Y.; Lu, Y.; Wang, Z.; Chen, B.; Zheng, Z. Preparation and Characterization of Biochars from Waste Camellia oleifera Shells by Different Thermochemical Processes. Energy Fuels 2017, 31, 8146-8151. [CrossRef]

25. Liang, J.; Qu, T.; Kun, X.; Zhang, Y.; Chen, S.; Cao, Y.-C.; Xie, M.; Guo, X. Microwave assisted synthesis of camellia oleifera shell-derived porous carbon with rich oxygen functionalities and superior supercapacitor performance. Appl. Surf. Sci. 2018, 436, 934-940. [CrossRef]

26. Zhang, L.; He, Y.; Zhu, Y.; Liu, Y.; Wang, X. Camellia oleifera shell as an alternative feedstock for furfural production using a high surface acidity solid acid catalyst. Bioresour. Technol. 2018, 249, 536-541. [CrossRef] [PubMed]

27. Mikkola, J.-P.; Hanna, V.; Tapio, S.; Rainer, S.; Tapio, O.; Juhani, V. Deactivation kinetics of Mo-supported Raney Ni catalyst in the hydrogenation of xylose to xylitol. Appl. Catal. A Gen. 2000,196, 143-155. [CrossRef]

28. Feher, A.; Feher, C.; Rozbach, M.; Racz, G.; Fekete, M.; Hegedus, L.; Barta, Z. Treatments of Lignocellulosic Hydrolysates and Continuous-Flow Hydrogenation of Xylose to Xylitol. Chem. Eng. Technol. 2018, 41, 496-503. [CrossRef]

29. Mishra, D.K.; Dabbawala, A.A.; Hwang, J.-S. Ruthenium nanoparticles supported on zeolite $\mathrm{Y}$ as an efficient catalyst for selective hydrogenation of xylose to xylitol. J. Mol. Catal. A Chem. 2013, 376, 63-70. [CrossRef]

30. Morales, R.; Campos, C.H.; Fierro, J.L.G.; Fraga, M.A.; Pecchi, G. Stable reduced Ni catalysts for xylose hydrogenation in aqueous medium. Catal. Today 2018, 310, 59-67. [CrossRef]

31. Morales, R.; Campos, C.H.; Fierro, J.L.G.; Fraga, M.A.; Pecchi, G. Perovskite as nickel catalyst precursor - impact on catalyst stability on xylose aqueous-phase hydrogenation. RSC Adv. 2016, 6, 67817-67826. [CrossRef]

32. Morales, R.; Campos, C.H.; Fierro, J.L.G.; Fraga, M.A.; Pecchi, G. Enhancing xylose aqueous-phase hydrogenation catalytic performance of A-site Ce substituted and B-site Rh doped reduced perovskites. Mol. Catal. 2017, 436, 182-189. [CrossRef]

33. Scholz, D.; Aellig, C.; Mondelli, C.; Perez-Ramirez, J. Continuous Transfer Hydrogenation of Sugars to Alditols with Bioderived Donors over Cu-Ni-Al Catalysts. Chem CatChem 2015, 7, 1551-1558. [CrossRef]

34. Mishra, D.K.; Dabbawala, A.A.; Hwang, J.-S. Poly (styrene-co-divinylbenzene) amine functionalized polymer supported ruthenium nanoparticles catalyst active in hydrogenation of xylose. Catal. Commun. 2013, 41, 52-55. [CrossRef]

35. Tung Ngoc, P.; Samikannu, A.; Rautio, A.-R.; Juhasz, K.L.; Konya, Z.; Warna, J.; Kordas, K.; Mikkola, J.-P. Catalytic Hydrogenation of D-Xylose Over Ru Decorated Carbon Foam Catalyst in a SpinChem (R) Rotating Bed Reactor. Top. Catal. 2016, 59, 1165-1177.

36. Hernandez-Mejia, C.; Gnanakumar, E.S.; Olivos-Suarez, A.; Gascon, J.; Greer, H.F.; Zhou, W.; Rothenberg, G.; Shiju, N.R. Ru/ $/ \mathrm{TiO}_{2}$-catalysed hydrogenation of xylose: The role of the crystal structure of the support. Catal. Sci. Technol. 2016, 6, 577-582. [CrossRef]

37. Xu, S.; Yan, X.; Bu, Q.; Xia, H. Catalytic conversion of cellulose into polyols using carbon-nanotube-supported monometallic Pd and bimetallic Pd-Fe catalysts. Cellulose 2017, 24, 2403-2413. [CrossRef]

38. Yang, F.; Liu, D.; Wang, H.; Liu, X.; Han, J.; Ge, Q.; Zhu, X. Geometric and electronic effects of bimetallic $\mathrm{Ni}-\mathrm{Re}$ catalysts for selective deoxygenation of m-cresol to toluene. J. Catal. 2017, 349, 84-97. [CrossRef]

39. Liu, H.; Huang, Z.; Kang, H.; Li, X.; Xia, C.; Chen, J.; Liu, H. Efficient bimetallic $\mathrm{NiCu}^{-\mathrm{SiO}_{2}}$ catalysts for selective hydrogenolysis of xylitol to ethylene glycol and propylene glycol. Appl. Catal. B Environ. 2018, 220, 251-263. [CrossRef]

40. Xia, H.; An, J.; Hong, M.; Xu, S.; Zhang, L.; Zuo, S. Aerobic oxidation of 5-hydroxymethylfurfural to 2,5-difurancarboxylic acid over Pd-Au nanoparticles supported on Mg-Al hydrotalcite. Catal. Today 2019, 319, 113-120. [CrossRef] 
41. Miao, M.; Zuo, S.; Zhao, Y.; Wang, Y.; Xia, H.; Tan, C.; Gao, H. Selective oxidation rapidly decomposes biomass-based activated carbons into graphite-like crystallites. Carbon 2018, 140, 504-507. [CrossRef]

42. Xia, D.; Chen, Y.; Li, C.; Liu, C.; Zhou, G. Carbon dioxide reforming of methane to syngas over ordered mesoporous Ni/KIT-6 catalysts. Int. J. Hydrog. Energy 2018, 43, 20488-20499. [CrossRef]

43. Chen, S.; Zhou, G.; Xie, H.; Jiao, Z.; Zhang, X. Hydrodeoxygenation of methyl laurate over the sulfur-free $\mathrm{Ni} /$ gamma- $\mathrm{Al}_{2} \mathrm{O}_{3}$ catalysts. Appl. Catal. A Gen. 2019, 569, 35-44. [CrossRef]

44. Ma, L.; Sun, K.; Luo, M.; Yan, L.; Jiang, Z.; Lu, A.-H.; Ding, Y. Role of ReOx Species in Ni-Re/ $\mathrm{Al}_{2} \mathrm{O}_{3}$ Catalyst for Amination of Monoethanolamine. J. Phys. Chem. C 2018, 122, 23011-23025. [CrossRef]

(C) 2019 by the authors. Licensee MDPI, Basel, Switzerland. This article is an open access article distributed under the terms and conditions of the Creative Commons Attribution (CC BY) license (http://creativecommons.org/licenses/by/4.0/). 